\title{
Suggestion of a major gene for familial febrile convulsions mapping to $8 \mathrm{q} 13-21$
}

\author{
R H Wallace, S F Berkovic, R A Howell, G R Sutherland, J C Mulley
}

\begin{abstract}
Febrile convulsions affect 2 to $5 \%$ of all children under the age of 5 years. These convulsions probably have a variety of causes, but a genetic component has long been recognised. A large and remarkable family is described in which febrile convulsions appear to result from autosomal dominant inheritance at a single major locus. A gene for febrile convulsions was excluded from regions of previously mapped epilepsy genes and extension of exclusion mapping, using microsatellite markers, to the entire genome implied that a locus on chromosome 8q13-21 may be involved. Linkage analysis of markers on chromosome 8 gave a multipoint lod score of 3.40, maximised over different values of penetrance and phenocopy rate, for linkage between the gene for febrile convulsions and the region flanked by markers D8S553 and D8S279. This lod score was calculated assuming the disease has a penetrance of $60 \%$ and a phenocopy rate of $3 \%$. Although there was no indication of linkage other than to markers on chromosome 8, linkage remains suggestive rather than significant because of the maximisation procedure applied. The support for linkage involving a major gene, as opposed to an alternative hypothesis of a complex inheritance pattern, relied upon the assumption of low penetrance.

( $f$ Med Genet 1996;33:308-312)
\end{abstract}

Key words: febrile convulsions; chromosome 8; genetic linkage.

Febrile convulsions are seizures usually occurring between 3 months and 5 years of age, associated with fever but without evidence of intracranial infection or other defined cause. ${ }^{1}$ They account for the majority of all childhood convulsive disorders, with $2-5 \%$ of all children likely to have at least one febrile convulsion. ${ }^{2}$ Although these seizures are benign, in some cases $(<4 \%)$ afebrile seizures may occur at a later date. ${ }^{3}$ A family history of febrile convulsions is often found, which could indicate a common environmental or a genetic basis. A range of genetic models has been proposed to explain the reported family history of febrile convulsions including autosomal recessive, autosomal dominant, and polygenic or multifactorial inheritance. ${ }^{4}$ Even if the majority of genetically determined febrile seizures arise from polygenic inheritance, study of rare families in which the disorder is caused by a major locus may enable its identification by linkage analysis.

Linkage between febrile convulsions and a particular chromosomal region has not yet been established. This is in part owing to difficulty in identifying single large families suitable for a successful linkage study. During a twin study of the epilepsies, a large Australian family with an autosomal dominant pattern of febrile convulsions was ascertained. ${ }^{5}$ Segregation of the phenotype in a single family provides a unique opportunity to identify the chromosomal location of a gene for this important childhood disorder. This eliminates interfamilial genetic heterogeneity as a confounding effect in linkage analysis. Nevertheless, the possibility of intrafamilial genetic heterogeneity remains, and the sensitivity of the analysis is reduced by incomplete penetrance and the possible presence of phenocopies. Despite this, genetic linkage analysis suggested that a locus on chromosome 8q13-21 may be associated with febrile convulsions in this family.

\section{Materials and methods}

THE FAMILY

Linkage analysis was performed on a large Australian family spanning three generations (fig 1). Family members underwent a structured interview, developed from a previously published seizure questionnaire ${ }^{6}$ with additional specific questions regarding onset, timing, frequency, and circumstances of febrile seizures.

Twenty-three subjects in this pedigree were identified with seizures and four were excluded from the analysis. Subject IV 8 had seizures associated with an early fatal childhood encephalopathy and was regarded as having a different condition. Subject III 26 had febrile convulsions but is unrelated to the test family; therefore he and his two affected children (IV·37, IV·38) were also omitted.

The other 19 subjects were considered as affected. All but one (II-1) had known febrile seizures. She is now aged 72 years, and therefore information regarding her early childhood may have been inaccurate. As she had a son with definite febrile seizures she was regarded as an obligate carrier of febrile seizures although she was not affected herself.

Of the 18 subjects with documented febrile seizures, 10 had a single attack, two had two attacks, and six had three or more attacks. The age of onset of the febrile seizures was 5 to 72 months (mean 17.6 (SD 16.1) months, median $12 \cdot 5)$. One person (II.4) was reported to have had a febrile seizure at the age of 6 years; all
Received 4 September 1995 Revised version accepted for publication 29 November 1995 


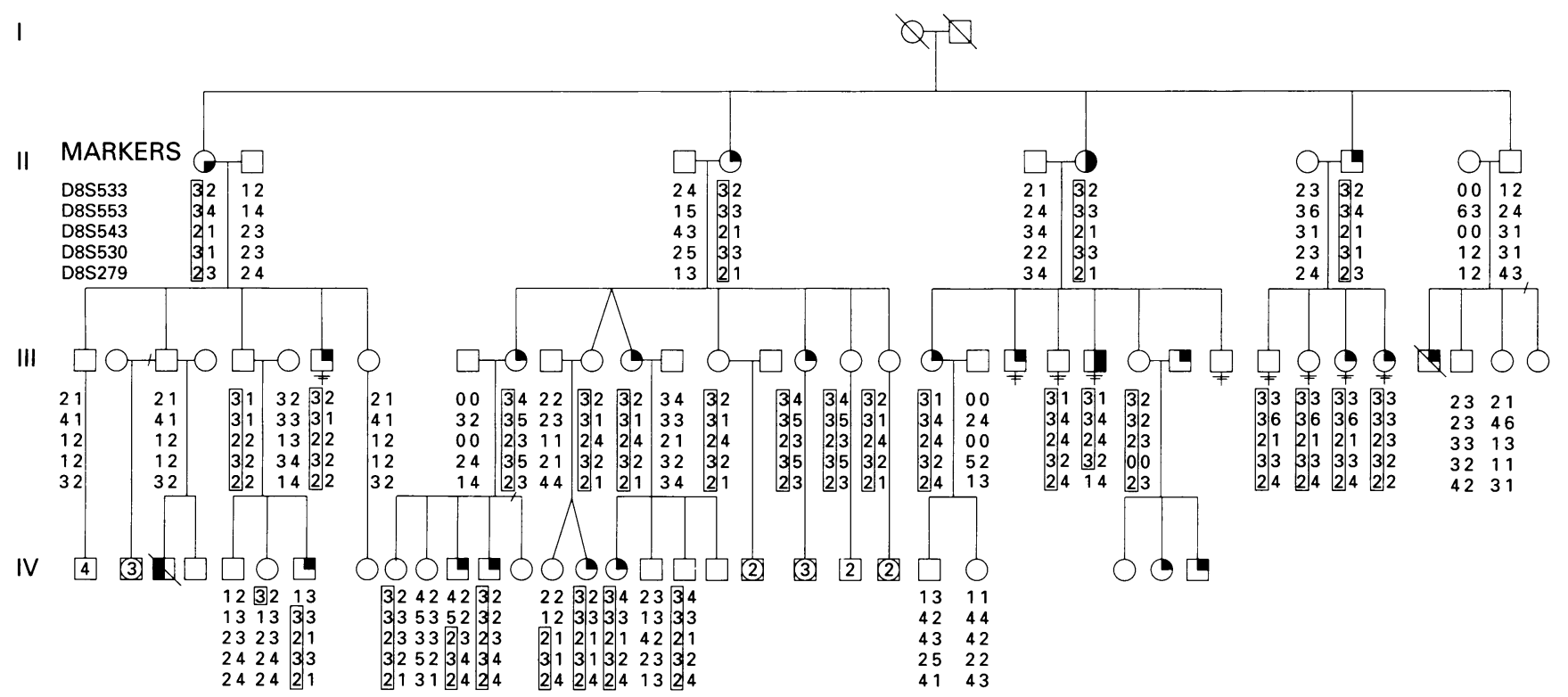

\begin{tabular}{|l|l|}
\hline Seizures with neonatal Febrile convulsion \\
encephalopathy
\end{tabular}

Pedigree showing a large Australian family with an autosomal dominant pattern of febrile convulsions. Chromosome 8 marker haplotypes are shown, which cover approximately $8 c M$ in the region 8q13-8q21, between the markers D8S533 and D8S279.

the others had an age of onset at 3 years or younger. The mean age of cessation of febrile seizures was 23 (SD 17) months and the median age of cessation was 18 months. The convulsions were generally brief although six subjects attended hospital for their attacks. Most attacks occurred in relation to suspected upper respiratory tract infections.

Three of the 19 affected subjects had afebrile seizures. Subject II 6 had complex partial seizures and secondarily generalised seizures from the age of 39 years, associated with left hippocampal sclerosis on magnetic resonance imaging. She is treated with carbamazepine but continues to have approximately 10 seizures per year. She had had approximately six febrile seizures from the age of 7 months until 1 year of age. The longest attack was reported to last approximately five minutes. Subject II 11 had two nocturnal seizures at the age of 48 and 50 years and was on carbamazepine. Subject III $\cdot 24$ had two seizures at the age of 17 years following a leptospirosis infection. $\mathrm{He}$ is now aged 29 and has had no further seizures, and is not on medication.

\section{GENOTYPING}

The genome search for the location of the febrile convulsion gene began with the analysis of markers in candidate regions, based on previously mapped epilepsies. ${ }^{7}$ The search was then extended by choosing additional loci at approximately $20 \mathrm{cM}$ intervals along the remaining chromosomes. Highly polymorphic microsatellite markers were chosen primarily from the Genethon linkage map. ${ }^{8}$ Amplification of $100 \mathrm{ng}$ of DNA was performed using conditions described by Phillips et al. ${ }^{9}$ Products were separated on $5 \%$ denaturing poly- acrylamide gels and visualised by autoradiography.

\section{LINKAGE ANALYSIS}

Genotyping was initially carried out using only members of the family affected with febrile seizures and their parents (where available). This saved considerable time because linkage to many loci could be excluded rapidly. When linkage to a marker was not excluded using only the affected members, the entire family was genotyped.

The disorder, defined as one or more febrile seizures, ${ }^{1}$ was initially analysed as an autosomal dominant trait with $80 \%$ penetrance, assuming the frequency of the affected allele to be 0.0001 . Two point linkage analysis was performed using the program MLINK, from the LINKAGE package. ${ }^{10}$ The lod scores generated by this program were further examined using the EXCLUDE program ${ }^{11}$ to summarise the exclusions generated by multiple two point lod scores. Any regions of the genome not adequately excluded were highlighted and remained areas of possible linkage assuming autosomal dominant inheritance.

Once the gene was assigned to a chromosome, two point lod scores (using data from the entire family) were recalculated using various conditions. These included a range of penetrances from $60 \%$ to $80 \%$, and inclusion of a $3 \%$ phenocopy rate. Multipoint lod scores were calculated for the same conditions described above using LINKMAP from the LINKAGE package. ${ }^{12}$ Four microsatellite markers were used in each LINKMAP run; for each subsequent run one new marker was incorporated into the analysis, and one marker from the previous run dropped. In this way the disease 
Table 1 Summary of results generated by the EXCLUDE program. (A) Initial genome search (275 markers, $80 \%$ penetrance); (B) result of genome search with 290 markers ( $80 \%$ penetrance); (C) column $B$ reanalysed at $60 \%$ penetrance with a $3 \%$ phenocopy rate; (D) only subjects who experienced multiple febrile convulsions included ( $80 \%$ penetrance)

Chromosome Percent probability of a locus being on a given chromosome

\begin{tabular}{|c|c|c|c|c|}
\hline & $A$ & $B$ & $C$ & $D$ \\
\hline 1 & 0.13 & 0.00 & 0.00 & 0.29 \\
\hline 2 & $7 \cdot 91$ & 0.00 & 0.00 & $82 \cdot 06$ \\
\hline 3 & 0.22 & 0.00 & 0.00 & $1 \cdot 23$ \\
\hline 4 & 0.01 & 0.00 & 0.00 & 0.00 \\
\hline 5 & 1.62 & 0.00 & 0.00 & $1 \cdot 74$ \\
\hline 6 & 0.67 & 0.00 & 0.00 & 0.25 \\
\hline 7 & 0.04 & 0.00 & 0.00 & $0 \cdot 10$ \\
\hline 8 & $8 \cdot 42$ & $99 \cdot 96$ & $100 \cdot 00$ & $3 \cdot 24$ \\
\hline 9 & $0 \cdot 10$ & 0.00 & 0.00 & 1.35 \\
\hline 10 & 0.72 & 0.00 & 0.00 & 7.95 \\
\hline 11 & 0.00 & 0.00 & 0.00 & 0.18 \\
\hline 12 & $33 \cdot 40$ & 0.00 & 0.00 & 0.56 \\
\hline 13 & 0.01 & 0.00 & 0.00 & 0.50 \\
\hline 14 & $46 \cdot 21$ & 0.02 & 0.00 & 0.00 \\
\hline 15 & 0.24 & 0.00 & 0.00 & 0.23 \\
\hline 16 & 0.12 & 0.00 & 0.00 & 0.04 \\
\hline 17 & 0.01 & 0.00 & 0.00 & 0.00 \\
\hline 18 & 0.00 & 0.00 & 0.00 & 0.03 \\
\hline 19 & $0 \cdot 13$ & 0.00 & 0.00 & 0.00 \\
\hline 20 & 0.00 & 0.00 & 0.00 & 0.00 \\
\hline 21 & 0.01 & 0.00 & 0.00 & $0 \cdot 16$ \\
\hline 22 & 0.03 & 0.00 & 0.00 & 0.07 \\
\hline
\end{tabular}

locus was analysed relative to a window of four marker loci at a time.

\section{Results}

Initially, areas corresponding to previously mapped epilepsies were examined $(6 \mathrm{p}, 8 \mathrm{p}$, $8 \mathrm{q} 24,10 \mathrm{q}, 20 \mathrm{q} 13.2$, and $21 \mathrm{q} 22.3$ ). None of the markers in these chromosomal regions indicated linkage to the febrile convulsion gene. Two point lod scores of 275 markers distributed throughout the genome were then analysed using the EXCLUDE program. This calculated the percent probability of a locus being on a given chromosome, with the results presented in a graphic format. The most likely positions for the febrile convulsion gene, by exclusion, were chromosomes $2,8,12$, and 14 (table 1A) assuming autosomal dominant inheritance of a major locus.

Additional markers were then genotyped from chromosomes $2,8,12$, and 14 , and their lod scores added to the original data. The resulting EXCLUDE map then showed a single peak on chromosome 8 , with a probability of $99.96 \%$ that the febrile convulsion gene was in this area (table 1B). The pairwise lod scores of markers covering this region gave a maximum of 2.91 at a recombination frequency of 0.05 for the marker D8S543 (table 2A). This lod score was calculated using only the affected members of the family. When these markers were reanalysed including all family members, the lod score for marker D8S543 dropped to $1 \cdot 16$ (table 2B). The maximum lod score obtained when the entire family was genotyped was $2 \cdot 25$ at a recombination frequency of 0 for marker D8S530 (which maps to the same region as D8S543). Penetrance is unknown, hence $80 \%$, as used in this stage of the analysis, must be considered as a very rough approximation.
Based on the assumption that the gene is located on chromosome 8 , all of the 16 affected subjects tested had the same genotype, and 13 unaffected subjects were apparent carriers. Three of these (II 1 , III $\cdot 5$, III 12 ) are obligate carriers. This indicated a penetrance of around $60 \%$, rather than $80 \%$ as first assumed. Based on this finding the markers in table $2 \mathrm{~B}$ were reanalysed at $60 \%, 70 \%$, and $80 \%$ penetrance (table 3 ). The two point lod score rose from 2.25 at $80 \%$ penetrance to $2 \cdot 82$ at $60 \%$ penetrance.

Another factor that may be affecting the analysis is the presence of phenocopies. Given that the occurrence of febrile convulsions in the population is around 3\%, there is the possibility of two or three phenocopies in this large family ( 88 subjects). One affected subject (III-26) was obviously a phenocopy because he was not related to the family of interest. Although this person and his children were omitted from the overall study, his spouse and two affected children had the chromosome 8 marker haplotype associated with the disease genotype. This suggested that the mother could be a carrier and that her children's febrile convulsions could be the result of inheritance of a gene from their mother. Subject III.32, who had only a single convulsion, may also be a phenocopy because his unaffected father (II-10) does not have the marker haplotype associated with the disease.

To account for possible phenocopies, the data were reanalysed at $60 \%, 70 \%$, and $80 \%$ penetrance with a $3 \%$ phenocopy rate (table 3 ). The inclusion of a phenocopy rate in the two point analysis decreased the lod score, because the affected subjects are now considered possible phenocopies. At $60 \%$ penetrance the multipoint lod score determined by LINKMAP analysis rose to 3.40 when a $3 \%$ phenocopy rate was included. To ensure the rest of the genome was still excluded when a penetrance of $60 \%$ and a $3 \%$ phenocopy rate was used, two point lod scores of 290 markers were reanalysed using these conditions. The lod scores were then examined using the EXCLUDE program (table 1C) which showed chromosome 8 was the only likely position of a gene for febrile convulsions in this family, when the penetrance is $60 \%$ and the phenocopy rate is $3 \%$. When subject III. 32 was omitted from the analysis the lod score rose to 3.41 at D8S543 (60\% penetrance). This procedure selectively chooses only those parts of the family that fit the data and therefore cannot be considered proof of linkage. It does, however, give an indication of how this single person has affected the probability that the gene responsible for febrile convulsions is located on chromosome 8 . The multipoint lod score of 3.40 previously determined, including III $\cdot 32$ in the analysis, remains suggestive of linkage.

The analysis was also affected by the fact that several of the markers were uninformative for large parts of the family. At present, no additional markers known to us map to this region of chromosome 8 . From these data it can only be concluded that this is the most likely position of the gene responsible for febrile 
Table 2 Two point lod scores between the febrile convulsion gene and markers on chromosome 8q13-21 (80\% penetrance). These markers span a region of approximately $16 \mathrm{cM}$. (A) Lod scores calculated using affected family members only; (B) lod scores calculated using the entire family

\begin{tabular}{|c|c|c|c|c|c|c|c|c|c|}
\hline \multirow[t]{2}{*}{ Locus } & \multicolumn{9}{|l|}{$\theta$} \\
\hline & 0.0 & 0.01 & 0.05 & $0 \cdot 1$ & $0 \cdot 2$ & $0 \cdot 3$ & 0.4 & $Z \max$ & $\theta \max$ \\
\hline \multicolumn{10}{|l|}{ (A) Affected only } \\
\hline GGAA8G07 & & $-2 \cdot 36$ & $\begin{array}{r}-0.68 \\
-0.58\end{array}$ & 0.09 & 0.53 & 0.45 & $0 \cdot 14$ & 0.54 & $0 \cdot 22$ \\
\hline D8S260 & 0.62 & 0.61 & 0.38 & 0.33 & 0.40 & $0 \cdot 25$ & $0 \cdot 11$ & 0.62 & 0.00 \\
\hline D8S510 & $-4 \cdot 41$ & $-2 \cdot 18$ & -0.90 & -0.39 & -0.01 & 0.09 & 0.07 & 0.09 & $0 \cdot 30$ \\
\hline D8S512 & -0.45 & 0.43 & 0.91 & 0.97 & $0 \cdot 80$ & 0.50 & $0 \cdot 17$ & 0.97 & $0 \cdot 10$ \\
\hline D8S544 & $-2 \cdot 69$ & -0.56 & 0.45 & 0.67 & 0.53 & $0 \cdot 20$ & 0.04 & $0 \cdot 68$ & $0 \cdot 12$ \\
\hline D8S533 & $-4 \cdot 21$ & -0.67 & 1.00 & 1.50 & 1.54 & $1 \cdot 03$ & 0.05 & $1 \cdot 60$ & $0 \cdot 16$ \\
\hline D8S553 & $-2 \cdot 26$ & -0.42 & 0.65 & 0.96 & 0.96 & 0.68 & $0 \cdot 31$ & $1 \cdot 01$ & $0 \cdot 16$ \\
\hline D8S543 & $2 \cdot 11$ & $2 \cdot 62$ & $2 \cdot 91$ & $2 \cdot 76$ & $2 \cdot 23$ & 1.47 & $0 \cdot 62$ & $2 \cdot 91$ & 0.05 \\
\hline D8S530 & $2 \cdot 52$ & $2 \cdot 47$ & $2 \cdot 26$ & $2 \cdot 00$ & 1.45 & 0.90 & $0 \cdot 39$ & $2 \cdot 52$ & 0.00 \\
\hline D8S279 & -0.77 & 0.77 & 1.72 & 1.90 & 1.65 & 1.08 & $0 \cdot 41$ & 1.90 & $0 \cdot 10$ \\
\hline 541 & $-2 \cdot 28$ & -0.61 & 0.64 & $1 \cdot 10$ & $1 \cdot 14$ & $0 \cdot 76$ & $0 \cdot 27$ & $1 \cdot 20$ & $0 \cdot 16$ \\
\hline D8 & -4.88 & $-1 \cdot 83$ & $-0 \cdot 25$ & 0.45 & $0 \cdot 81$ & 0.66 & $0 \cdot 31$ & $0 \cdot 81$ & $0 \cdot 20$ \\
\hline \multicolumn{10}{|l|}{ (B) Entire family } \\
\hline GGAA8G0 & $-8 \cdot 89$ & $-4 \cdot 60$ & -1.97 & -0.73 & $0 \cdot 27$ & 0.48 & $0 \cdot 24$ & $0 \cdot 48$ & $0 \cdot 30$ \\
\hline D8S260 & 0.54 & 0.55 & 0.59 & 0.61 & 0.55 & 0.40 & $0 \cdot 20$ & $0 \cdot 61$ & $0 \cdot 10$ \\
\hline D8S510 & $-7 \cdot 22$ & $-3 \cdot 60$ & $-1 \cdot 70$ & -0.85 & $-0 \cdot 14$ & 0.09 & $0 \cdot 10$ & $0 \cdot 10$ & 0.40 \\
\hline 512 & $-2 \cdot 84$ & $-2 \cdot 01$ & $-1 \cdot 19$ & -0.75 & -0.30 & -0.12 & -0.06 & -0.06 & 0.40 \\
\hline D8S544 & $-6 \cdot 79$ & $-4 \cdot 33$ & $-2 \cdot 72$ & -1.86 & -0.97 & -0.50 & $-0 \cdot 23$ & -0.23 & 0.40 \\
\hline D8S533 & $-7 \cdot 93$ & $-3 \cdot 48$ & $-1 \cdot 23$ & $-0 \cdot 20$ & 0.63 & 0.73 & 0.40 & 0.75 & 0.25 \\
\hline D8S553 & $-2 \cdot 51$ & -0.22 & 1.02 & 1.46 & 1.56 & $1 \cdot 20$ & $0 \cdot 61$ & 1.59 & $0 \cdot 15$ \\
\hline D8S543 & $-0 \cdot 88$ & -0.39 & $0 \cdot 39$ & 0.85 & $1 \cdot 15$ & 0.99 & $0 \cdot 50$ & $1 \cdot 16$ & $0 \cdot 21$ \\
\hline D8S530 & $2 \cdot 25$ & $2 \cdot 25$ & $2 \cdot 23$ & $2 \cdot 13$ & $1 \cdot 76$ & $1 \cdot 22$ & 0.59 & $2 \cdot 25$ & 0.00 \\
\hline 79 & $-4 \cdot 19$ & $-2 \cdot 41$ & -0.88 & $-0 \cdot 11$ & 0.53 & 0.58 & $0 \cdot 27$ & 0.61 & 0.25 \\
\hline $\mathrm{D} \varepsilon$ & $-5 \cdot 42$ & $-3 \cdot 34$ & $-1 \cdot 38$ & -0.38 & 0.41 & 0.51 & $0 \cdot 26$ & 0.53 & $0 \cdot 27$ \\
\hline D8S286 & $\cdot 35$ & $-5 \cdot 40$ & $-2 \cdot 81$ & -1.44 & -0.21 & $0 \cdot 20$ & 0.20 & 0.24 & 0.35 \\
\hline
\end{tabular}

Table 3 Summary of the maximum lod scores calculated assuming various conditions

\begin{tabular}{|c|c|c|c|c|c|}
\hline \multirow{2}{*}{$\begin{array}{l}\text { Penetrance } \\
(\%)\end{array}$} & \multirow{2}{*}{$\begin{array}{l}\text { Phenocopy rate } \\
\text { (\%) }\end{array}$} & \multicolumn{2}{|l|}{ Two point } & \multicolumn{2}{|c|}{ Multipoint } \\
\hline & & Max lod & Marker & Max lod & Marker \\
\hline $\begin{array}{l}60 \\
60 \\
70 \\
70 \\
80 \\
80\end{array}$ & $\begin{array}{l}\overline{3} \\
\overline{3} \\
\overline{3}\end{array}$ & $\begin{array}{l}2 \cdot 82 \\
2 \cdot 53 \\
2 \cdot 64 \\
2 \cdot 24 \\
2 \cdot 25 \\
1 \cdot 86\end{array}$ & $\begin{array}{l}\text { D8S530 } \\
\text { D8S543 } \\
\text { D8S530 } \\
\text { D8S530 } \\
\text { D8S530 } \\
\text { D8S530 }\end{array}$ & $\begin{array}{l}1 \cdot 84 \\
3 \cdot 40 \\
1 \cdot 22 \\
2 \cdot 88 \\
0 \cdot 84 \\
1.91\end{array}$ & $\begin{array}{l}\text { D8S553-543 } \\
\text { D8S553-543 } \\
\text { D8S553-543 } \\
\text { D8S553-543 } \\
\text { D8S553-543 } \\
\text { D8S553-543 }\end{array}$ \\
\hline
\end{tabular}

convulsions in this family, based on the assumption that a major gene with autosomal dominant inheritance produces the phenotype of one or more febrile convulsions.

One study suggested that families in which people experience single febrile convulsions were best described by the polygenic model of inheritance, and that in families with multiple febrile convulsions the data were consistent with a single major locus model..$^{13}$ Considering this, members of the febrile convulsions family shown in the figure were reanalysed with only those people who experienced unequivocal multiple febrile convulsions coded as affected. Subjects who experienced single convulsions were designated unknown when determining lod scores. Using these conditions the EXCLUDE map suggested a localisation to chromosome 2 as more likely than to chromosome 8 (table 1D). This likelihood reflects the fact that the chromosome 8 markers were less informative than the chromosome 2 marker in this smaller part of the family, and does not exclude the chromosome 8 region. The maximum lod score at this position on chromosome 2 is 1.32 at a recombination frequency of 0.05 for marker D2S142. The small family now defined by this revised and very stringent clinical criteria no longer has the power to detect linkage, with the maximum possible lod score obtainable for a completely linked and fully informative marker being $1 \cdot 6$. The chromosome 2 data are thus meaningless as an indication for the location of a major gene or of a modifier gene for febrile convulsions.

\section{Discussion}

Febrile seizures are common and the proportion which have a genetic basis are probably genetically heterogeneous. In families where some people have later afebrile seizures, at least two clinical patterns are seen. First, febrile seizures may occur in families where there is a high frequency of later generalised epilepsy syndromes. Second, febrile seizures may occur in families where some subjects have temporal lobe epilepsy with associated hippocampal sclerosis. The current family fits into the second group. Our linkage results suggest that a major gene for this pattern of familial febrile convulsions is located on chromosome 8. Exclusion of chromosomal regions to which other epilepsies map indicate that febrile convulsions are not allelic to these disorders. This is not surprising since the epilepsies mapped so far, including three idiopathic generalised and two idiopathic partial epilepsies, ${ }^{7}$ are clinically very different from febrile convulsions.

Exclusion mapping throughout the human genome showed that the most likely position of the febrile convulsion gene is chromosome 8q13-21. All of the affected subjects tested have the same genotype at this position (III. 32 was not tested), highly supportive of the assumption that the gene is in this area. However, 13 unaffected subjects (including three obligate carriers) also have the same genotype, suggesting a low penetrance of 60 to $65 \%$. When the possibility of phenocopies was taken into consideration, by incorporating a 3\% phenocopy rate, the maximum multipoint lod score was 3.40 between D8S553 and D8S279 (60\% penetrance). The region on chromosome 8 flanked by these markers covers approximately $8 \mathrm{cM}$ on the Genethon linkage map. ${ }^{8}$ Maximisation of the lod score over different penetrance and phenocopy values can inflate the lod score. On that basis, these linkage data must be regarded as suggestive rather than significant.

If a major gene for febrile convulsions in this family maps to this region of chromosome 8 it might be identified by the positional candidate approach. ${ }^{14}$ Candidate genes in this region of chromosome 8 include corticotrophin releasing hormone ${ }^{15}$ and calbindin. ${ }^{16}$ Using rat models, studies showed that both of these genes may have some involvement in seizures. ${ }^{1718}$ Other candidate genes, on the basis of neural expression, include peroxisomal assembly factor$1^{19}$ and peripheral myelin protein-2. ${ }^{20}$

Detection of linkage would support a hypothesis of autosomal dominant inheritance of a major gene in this family, with the phenotypic manifestations of one or more febrile convulsions. This is conditional upon one or more modifier loci mapping elsewhere, or an unknown environmental effect modifying the expression of a major locus on chromosome 8. If further linkage analyses applied to other families fails to confirm that a febrile convulsion gene maps to chromosome 8 , then there are 
two possibilities. One is that febrile convulsions are genetically heterogeneous. The other possibility is that the disorder may not be the result of inheritance of a single major locus. The lod score of $2 \cdot 25$ obtained for D8S530 (at $80 \%$ penetrance) may merely represent a chance finding, given the large number of two point lod scores that were determined. Some syndromes are presumed to result from the additive effect of a small number of genes. Such a polygenic aetiology is implicated in families with a history of single febrile convulsions. ${ }^{13}$ Alternatively, febrile convulsions may result from a combination of genetic and environmental causes (multifactorial inheritance) or environmental factors alone. With the common occurrence of febrile convulsions in the human population ( 2 to $5 \%$ ), the possibility of phenocopies within this family must also be considered. Another possibility is that the Genethon map does not extend to the telomeres of all chromosomes, and that a major gene for febrile convulsions in this family maps to one of these regions of high recombination not covered by the Genethon map.

The first gene responsible for an idiopathic epilepsy has recently been identified. ${ }^{21}$ Localising genes responsible for febrile seizures and epilepsies will have important consequences for diagnosis and treatment. Management and prophylaxis of febrile seizures remains controversial. The establishment of a linkage marker, and eventually a specific gene, would have direct implications in accurate counselling of parents, and in planning rational trials of prophylactic therapy.

This work was supported by the Women's and Children's Hospital Foundation, the National Health and Medical Research Council of Australia, and an International Research Scholars Award from the Howard Hughes Medical Institute (GRS).

1 Consensus Development Panel. Febrile seizures: long term Consensus Development Panel. Febrile seizures: long term management of children with
2 O'Donohoe NV. Febrile convulsions. In: Roger J, Bureau M, Dravet C, Dreifuss FE, Perret A, Wolf P, eds. Epileptic syndromes in infancy, childhood and adolescence. 2nd ed. London: John Libby Eurotext Ltd, 1992:45-52.

3 Nelson KB, Ellenberg JH. Febrile seizures. New York: Raven Press, 1981:360.

4 Gardiner RM. Genes and epilepsy. $\mathcal{F}$ Med Genet 1990;27: 537-44.

5 Berkovic SF, Howell RA, Hay DA, et al. The genetics of febrile convulsions: a twin study. Aust NZ f Med 1991; 21(suppl 1):177A.

6 Reutens DC, Howell RA, Gebert KE, Berkovic SF. Valdation of a questionnaire for clinical seizure diagnosis. Epilepsia 1992;33:1065-71.

7 Ryan SG. Partial epilepsy: chinks in the armour. Nature Genet 1995;10:4-6.

8 Gyapay G, Morisette J, Dib C, et al. The 1993-4 Genethon human genetic linkage map. Nature Genet 1994;7:246339.

9 Phillips HA, Scheffer IE, Berkovic SF, et al. Localisation of autosomal dominant nocturnal frontal lobe epilepsy to 20q13.2. Nature Genet 1995;10:117-18.

10 Lathrop GM, Lalouel JM. Easy calculations of lod scores and genetic risks on small computers. Am 7 Hum Genet 1984;36:460-5.

11 Edwards JH. Exclusion mapping. $f$ Med Genet 1987;24: 539-43.

12 Lathrop GM, Lalouel JM, Julier C, Ott J. Strategies for multilocus linkage analysis in humans. Proc Natl Acad Sci USA 1984;81:3443-6.

13 Rich SS, Annegers JF, Hauser WA, Anderson VE. Complex segregation analysis of febrile convulsions. Am $\mathcal{F}$ Hum Genet 1987;41:249-57.

14 Collins FS. Positional cloning moves from perditional to traditional. Nature Genet 1995;9:347-50.

15 Arbiser JL, Morton CC, Bruns GAP, Majzoub JA. Human corticotropin releasing hormone gene is located on the corticotropin releasing hormone gene is located on the long arm

16 Parmentier M, De Vijlder JJM, Muir E, et al. The human calbindin $27 \mathrm{kDa}$ gene: structural organisation of the 5 prime and 3-prime regions, chromosomal assignment and restriction fragment length polymorphism. Genomics 1989 4:309-19.

17 Smith BN, Dudek FE. Age-related epileptogenic effects of corticotropin-releasing hormone in the isolated CA1 region of rat hippocampal slices. $\mathcal{f}$ Neurophysiol 1994;72: 2328-33.

18 Tønder N, Kragh J, Finsen BR, et al. Kindling induces transient changes in neuronal expression of somatostatin, neuropeptide $\mathrm{Y}$, and calbindin in adult rat hippocampus neuropeptide Y, and calbindin in adult rat hippoca

19 Masuno M, Shimozawa N, Suzuki Y, et al. Assignment of the human peroxisome assembly factor-1 gene (PXMP3) responsible for Zellweger syndrome to chromosome $8 \mathrm{q} 21.1$ by fluorescence in situ hybridization. Genomics 1994;20:141-2.

20 Hayasaka K, Himoro M, Takada G, et al. Structure and localisation of the gene encoding human peripheral myelin protein 2 (PMP2). Genomics 1993;18:244-8.

21 Steinlein OK, Mulley JC, Propping P, et al. A missense mutation in the neuronal nicotinic acetylcholine recepto a4 subunit is associated with autosomal dominant nocturnal frontal lobe epilepsy. Nature Genet 1995;11:201-3. 